\title{
Optimal Location and Size for the Battery Energy Storage System Installation in a Microgrid
}

\author{
Nitikorn JUNHUATHON and Boonruang MARUNGSRI* \\ School of Electrical Engineering, Suranaree University of Technology, Thailand \\ ${ }^{*}$ Corresponding author
}

\begin{abstract}
Renewable Energy Source (RES) is unreliable because it fluctuates by itself. This problem can solve by Battery Energy Storage System (BESS) installation. Installation of BESS in each place cause different effects for the micro grid. This paper proposed a method for optimal location and optimal sizing to install BESS in a micro grid using Particle Swarm Optimization (PSO) technique. Wind power and solar power were the primary sources of power generation in this study. The IEEE standard 14 bus system was used, and the system was simulated via the MATLAB program. The simulation results showed that the installing of BESS at an optimal location reduced the consumption of power loss in the microgrid. Optimal size installation provided the ability of charge and discharged power enough to all load to maintain the voltage all bus in a day. Also, reduced the cost of investment from the un-optimal size of the BESS installation.
\end{abstract}

Keywords—microgrid; battery energy storage system; renewable energy source; optimal location; optimal size

\section{INTRODUCTION}

The microgrid is a system using distributed generation (DG) to provide electrical energy to consumers. Recently, RESs used worldwide because it has many advantages such as reducing pollution, sustainable energy [1][2]. The RES may be derived from PV, wind turbine or biomass depending on the properties of the area. The RES generated unreliable electrical energy because of itself fluctuation. Therefore, the microgrid system integrating with renewable energy system must install the energy storage system for store electric energy during over demand period and supply during under demand generation period. Energy storage system may be pumped hydro, compressed air, flywheel, battery, etc. Appropriate battery types for energy storage applications is considered as the main objective of the work. It is essential to focus on the main factors such as Power and space-to-energy ratio, energy efficiency, lifetime, spacing, installation costs, maintenance, technology, safety, etc. The BESS is suitable for the stored electrical energy from RES because of balance for energy storage, the appropriate price for microgrid and good stabilize for supply load. Factors influence the efficient of BESS include type, size, and location of installation.

For a decade, benefits of the energy storage have been researched worldwide. AC voltage regulator based battery charger was designed for the large-scale photovoltaic system [3]. The computer program was developed for the design of battery energy storage system for power users who have installed the photovoltaic system for maximum economic benefits [4]. The computer program was designed for scheduling and pricing of energy storage systems [5]. However, optimal installation location and optimal size are not yet the consideration.

Therefore, this paper proposes the method to identify optimal location and size for the installation of BESSs for microgrid system by power flow analysis method and loss analysis. For reducing power loss in the system, particle swarm optimization was used to solve the optimization problem.

\section{A. Battery Energy Storage System}

Energy of BESS at ${ }^{\tau}$ hour can determine as in equation (1)

$$
\mathrm{E}_{\tau+1}^{B E S S}=\mathrm{E}_{\tau}^{B E S S}+\left(\mathrm{P}_{\tau}^{P V}+\mathrm{P}_{\tau}^{W T}-P_{\tau}^{\text {Load }}-P_{\tau}^{\text {Loss }}\right) \Delta t
$$

The amount of energy in a period $\tau$ hour must not exceed the maximum energy for the BESS changeability and not less than the minimum energy requirement.

where

$$
\mathrm{E}^{\text {BESS_Min }} \leq \mathrm{E}_{\tau}^{\text {BESS }} \leq \mathrm{E}^{\text {BESS_Max }}
$$

$$
\mathrm{E}^{\text {BESS_Min }}=\text { Minimum Energy requirement }(\mathrm{kWh})
$$

$$
\mathrm{E}^{\text {BESS_Max }}=\quad \begin{gathered}
\text { The maximum energy of energy storage can } \\
\text { store }(\mathrm{kWh})
\end{gathered}
$$

\section{B. Power Flow Analysis}

The power flow analysis was used to analyze the bus voltage and power loss by the Newton Raphson method. The error size set is not over 0.001 for determining the bus voltage, and power loss occurring in the system at one day. Then the optimal location and the optimal size were determined by particle swarm optimization PSO. 


\section{Particle Swarm Optimization}

In this paper, particle swarm optimization (PSO) is used as an artificial intelligence technique. PSO technique is based on the stochastic optimization technique inspired by social behavior of fish schooling or birds flocking. Fish schooling and birds flocking represented by the particle. Position of individual particles updated as follows

$$
X_{k+1}^{i}=X_{k}^{i}+V_{k+1}^{i}
$$

With the velocity calculated as follows

$$
V_{k+1}^{i}=V_{k}^{i}+c_{1} r_{1}\left(P_{k}^{i}-X_{k}^{i}\right)+c_{2} r_{2}\left(P_{k}^{g}-X_{k}^{i}\right)
$$

Where

$$
\begin{gathered}
P_{k}^{i}=\text { best "remembered" individual particle } \mathrm{p} \\
P_{k}^{g}=\text { best "remembered" swarm position } \\
c_{1}, c_{2}=\text { cognitive and social parameters } \\
r_{1}, r_{2}=\text { random numbers between } 0 \text { and } 1
\end{gathered}
$$

\section{Methodology}

\section{A. Optimal Location}

The optimal location for the BESS installation was located after perform the power flow and the power loss analyses. Objective function to find the optimal location follow equation (1). The optimal location is the place for the BESS installation which giving less power loss in microgrid system. The voltage at every bus in the standard system is followed equation (5) and (6).

$$
\begin{aligned}
& F_{\text {place }}=\sum_{\tau=1}^{n} \text { place }_{\tau}^{\text {lessloss }} \\
& V_{\min }<V_{n}<V_{\max }
\end{aligned}
$$

The process of optimal location of the BESS installation is shown in Fig. I (a)

\section{B. Optimal Size}

The optimal size of the BESS can be chosen from the lack of energy under the load demand. Equation (7), and (8) are used to determine the optimal maximum and minimum size of the BESS. The flowchart to determine the optimal size of the BESS is shown in Fig. I (b)

$$
\mathrm{E}_{\min }^{\text {BESS_Size }}=\sum_{n \tau=1}^{n}\left(P_{n \tau}^{L o a d}+P_{n \tau}^{L o s s}-\mathrm{P}_{n \tau}^{P V}-\mathrm{P}_{n \tau}^{W T}\right) \Delta t
$$

Equation (7) shows total lack of energy generation of the system which less than the load demand. It is the minimum energy that the BESS needs to charge and discharge to load. The optimal size of the BESS must not exceed the difference between maximum energy generation and load demand. Equation (8) is used to determine the optimal size of the BESS.

$$
\text { OptimalSize }=\rho E_{\min }^{B E S S \_S i z e}
$$

where $\rho$ is a safety factor for power system

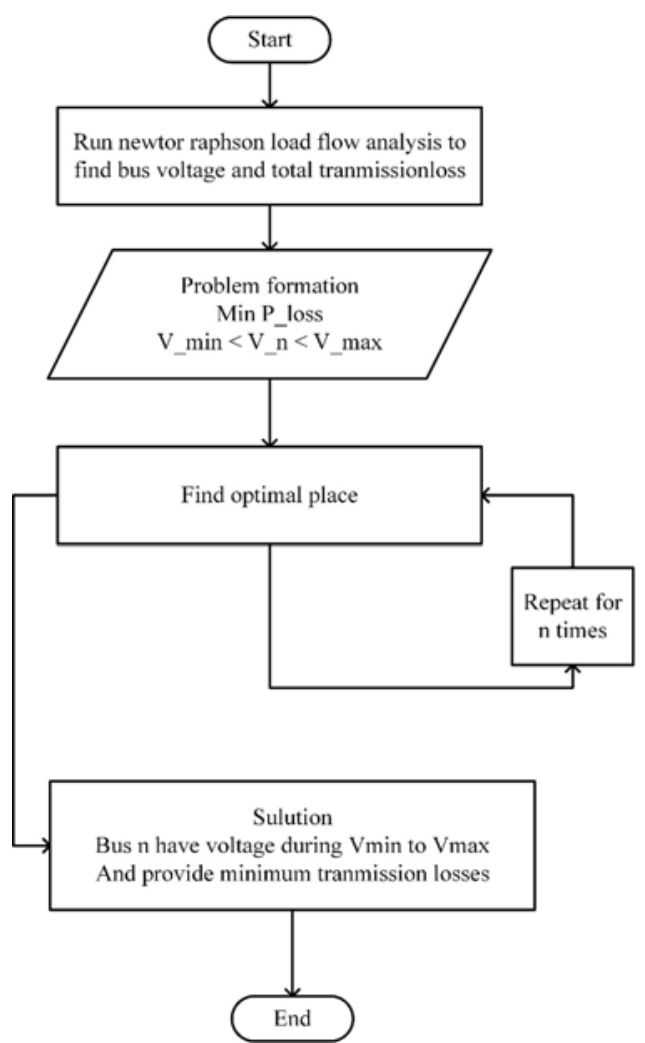

(a) 


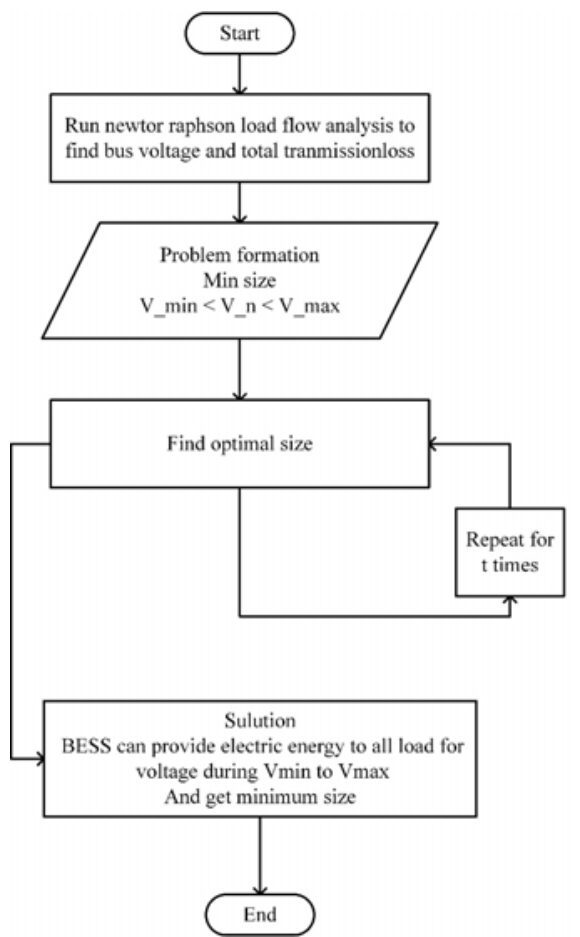

(b)

FIGURE I. (A) THE PROCESS OF THE OPTIMAL PLACEMENT OF THE BESS (B) THE PROCESS OF THE OPTIMAL SIZE OF THE BESS

\section{A CASE STUDY}

In this study, IEEE 14 bus standard system was used and was modified. For simulation, the IEEE 14 bus standard test system was modified by assign wind power generation at bus 1 , and solar power generation at bus 2, as shown in Fig. II.

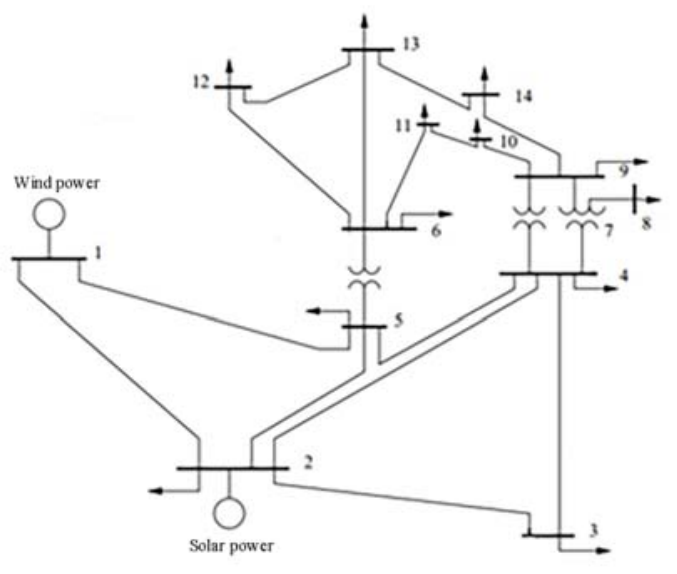

FIGURE II. IEEE 14 BUS STANDARD TEST SYSTEM

In this simulation, wind energy and solar energy were used as the primary energy sources for a simulation system. The solar energy and wind energy generations in one day are shown in Fig. III and the electric load demand in one day are shown in Fig. IV.

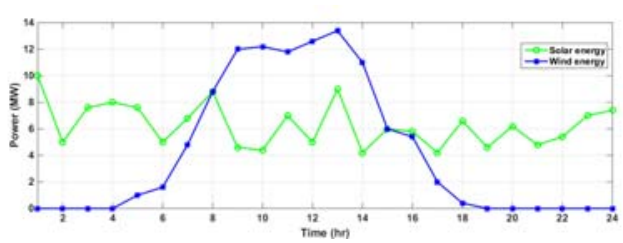

FIGURE III. WIND AND SOLAR POWER GENERATED IN PERIOD ONE DAY

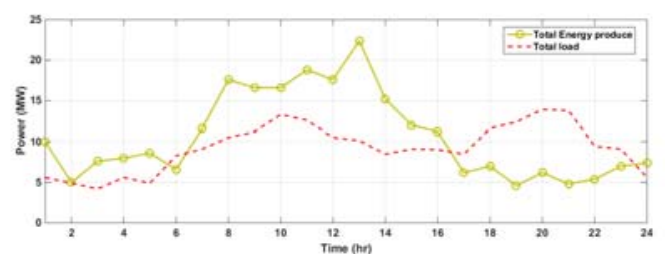

FIGURE IV. TOTAL LOAD AND TOTAL POWER GENERATION IN PERIOD ONE DAY

\section{RESUlTS AND DisCUSSION}

After analyzing the IEEE 14 bus standard system by power flow analysis and particle swarm optimization (PSO), the optimal location to install the BESS was bus 1. The BESS installation at bus 1 caused the power loss about $16.37 \mathrm{MW} /$ day which less than another bus as shown in Fig. V. In this case, the peak load demand of the microgrid is about $13.5 \mathrm{MW}$. It was found that power loss in the system increase along the expansion of power distribution system or the micro grid.

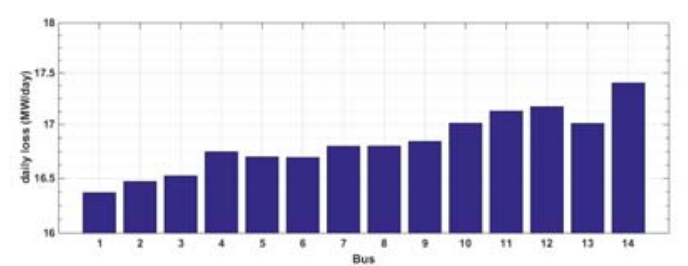

FIGURE V. POWER LOSS IN PERIOD ONE DAY AT BUS 1 TO 14

After identifying the optimal bus or location, the optimal size of the BESS was analyzed by PSO technique. The optimal size of BESS about $57 \mathrm{MW}$ was obtained from the simulation results. The power generation over the demand for use in the emergency case is shown in Fig. VI.

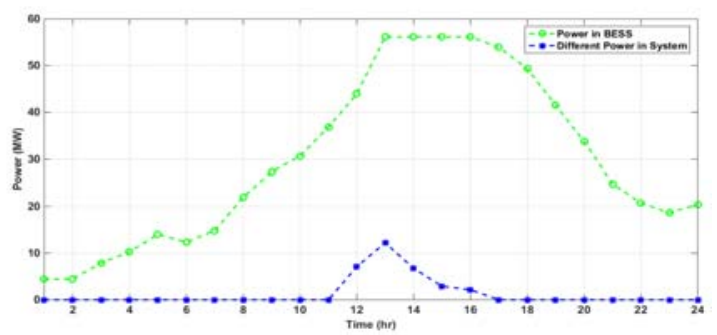

FIGURE VI. DIFFERENCE BETWEEN THE ENERGY GENERATION AND THE TOTAL LOAD DEMAND AFTER INSTALLING THE BESS INTO THE ELECTRICAL SYSTEM

After installing the optimal size of BESS into the system, no lack of power occurs in the system and leftover power in the system for use in an emergency condition. Concerning load 
curve in Fig. IV and remaining energy in BESS for 1 day in Fig. $\mathrm{V}$, the stored energy can be used for about two hours in peak load in case DG cannot operate. The results indicate that the size of the selected energy storage source is sufficient to use in the system under an emergency condition.

\section{CONCLUSION}

The optimal location and the optimal size of the BESS were determined by using PSO. Simulation results showed that power loss in the system is less than another location because of the place of installation high intensive power flow rate.The optimal size can use to store the energy and provide enough electric energy to all load in a day. This method can determine the minimum BESS capacity for charging and discharging energy to the load all day and reserving for an emergency event.The BESS size may increase or decrease depends on how much energy the system need to use in the emergency condition.

\section{REFERENCES}

[1] Plant, N., Cabrero, E., and Saha, T .K . Power plant efficiency reporting and online auditing system for carbon pollution. IEEE Power and Energy Society General Meeting. (2012) 1-6.

[2] Massaeli, M., Javadian, S .A., and Khalesi, N. Environmental benefits of DGs and comparing their generation costs with thermal power plants considering production pollution on human health .2011 International Conference on Power Engineering, Energy, and Electrical Drives. (2011)1-6.

[3] Vavilapalli, S., Subramaniam, U., Padmanaban, S., and Ramachandaramurthy, V .K .Design and Real-Time Simulation of an AC Voltage Regulator Based Battery Charger for Large-Scale PV-Grid Energy Storage Systems .IEEE Access. (2017) 25158 - 25170.

[4] Kusakana, K .Optimal scheduling of a grid-connected hydrokinetic-battery system under Time of Use tariff .2016 International Conference on the Domestic Use of Energy. (2016)1-6.

[5] Khatami, R., Parvania, M., and Khargonekar, P. Scheduling and Pricing of Energy Generation and Storage in Power Systems .IEEE Transactions on Power Systems. (2017)1-1. 